\title{
The "chicken-and-egg" development of political opinions The roles of genes, social status, ideology, and information
}

Peter Beattie, J.D.

Department of Political Science, University of California, Irvine

\begin{abstract}
Twin studies have revealed political ideology to be partially heritable. Neurological research has shown that ideological differences are reflected in brain structure and response, suggesting a direct genotype-phenotype link. Social and informational environments, however, also demonstrably affect brain structure and response. This leads to a "chicken-and-egg" question: do genes produce brains with ideological predispositions, causing the preferential absorption of consonant information and thereby forming an ideology, or do social and informational environments do most of the heavy lifting, with genetic evidence the spurious artifact of outdated methodology? Or are both inextricably intertwined contributors? This article investigates the relative contributions of genetic and environmental factors to ideological development using a role-play experiment investigating the development of opinions on a novel political issue. The results support the view that the process is bidirectional, suggesting that, like most traits, political ideology is produced by the complex interplay of genetic and (social/informational) environmental influences.
\end{abstract}

Key words: Genopolitics, ideology, twin studies, social status, public opinion

$\mathrm{R}$ ecent research has powerfully challenged the assumption that our political ideologies are formed exclusively through socialization. Instead, it now seems settled that genes also play a role in the formation of political ideologies and that contemporary politics can be accurately viewed, at least in part, as an evolutionary exaptation - a trait or suite of traits that evolved to serve one or several purposes but now serves a different purpose(s). Rather than ideology being a uniquely modern phenomenon produced only by social, economic, philosophical, and political developments, it seems to be just as much a product of biological evolution. ${ }^{1}$ That is, the evolutionary developments that allowed our species to effectively cooperate within groups and compete between groups are now playing a role in shaping contemporary political ideologies. Ideology is defined here according to Jost, Federico, and Napier's synthesis of critical and value-neutral understandings as "both genuine (and even highly accurate) attempts to understand, interpret, and organize information about the political world as well as

doi: $10.1017 /$ pls.2017.1

Correspondence: Peter Beattie, Department of Political Science, University of California, Irvine. Email: pbeattie@uci.edu conscious or unconscious tendencies to rationalize the way things are or, alternatively, the desire for them to be different." 2

There is substantial evidence that genes influence the development of political ideology and that political ideology correlates with the structure and response patterns of our brains. ${ }^{3,4}$ We also know that environmental factors are important determinants of political ideology: for example, a baby born to right-wing parents in the United States who is then adopted by a family in North Korea is entirely unlikely to develop an ideology of limited government and Christian values in her new home. Differences in political ideology, which can be observed on a neurological level, seem to be caused both by genes and by environmental factors. But are they primarily caused by genes, which set in motion a process by which we tend to select our environments and sources of information in accordance with our genetic ideological-predispositions? Or are they primarily caused by our environments, which set in motion a snowballing process by which we tend to select friends, schools, jobs, media sources, and the like that reinforce the ideology to which our initial familial environment predisposed us? This is what Jost, Noorbaloochi, 
and Van Bavel term the "chicken-and-egg problem," arguing that the solution is

a dynamic, recursive theoretical framework in which the connection between physiological (and psychological) functioning and political outcomes is conceived of as bidirectional rather than unidirectional. Political orientation, we submit, is the product of an "elective affinity" between the discursive, socially constructed elements of ideological belief systems and the psychological constraints, motives, and interests of those who are drawn to those belief systems. ${ }^{5}$

As a preliminary test of this proposed solution, this article uses a role-play method to test for the influence of both genes and (social/informational) environment on the development of opinions on a novel political proposal. It is hypothesized that the outcome (opinion) will be bidirectionally influenced by both sets of factors, providing a rough model of innumerable such instances of opinion formation over the long-term process of ideological development.

\section{Genetic effects on the development of political ideology}

Perhaps the easiest or most direct way to test for the effects of genes on human behaviors and dispositions arises from a kind of natural experiment provided by identical and fraternal twins. Identical (monozygotic) twins come from the same fertilized egg and share roughly $100 \%$ of their genes, while fraternal (dizygotic) twins come from two separate fertilized eggs and share roughly $50 \%$ of their genes, as do all siblings. Recent research has challenged this assumption, ${ }^{6}$ as epigenetic changes over the lifetime may make identical twins' DNA diverge. Hence, the first place to look for genetic effects on any trait is in the differences and similarities between identical and fraternal twins. If a sample of identical twins correlates at a rate of $80 \%$ on a given trait (for example, if 8 out of 10 identical twins have the same favorite flavor of ice cream), and a paired sample of fraternal twins correlates at a rate of $40 \%$ on that same trait (only 4 out of 10 share the same favorite flavor), then we can estimate that on the level of population (not the individual level), ice cream preferences are $40 \%$ heritable. In other words, $40 \%$ of the population-level variation in ice cream preferences can be linked to genetic heritability. The remaining $60 \%$ of variation can be ascribed to shared environmental influences (such as the ice cream flavors available at home), unique environmental influences (such as one's own friends and the influence of their flavor preferences), and measurement error.

Twin studies of political attitudes have consistently found that heritable genetic factors play a significant role. Opinions on political issues such as pacifism, socialism, capitalism, foreign aid, gay rights, and federal housing have been found to have a heritability component of $32 \%$ on average. ${ }^{7}$ Political ideology has been found to be $56 \%$ heritable, egalitarianism $50 \%$ heritable, and right-wing authoritarianism $48 \%$ heritable. ${ }^{8}$ Forms of political participation have been found to be partly heritable, with estimates of $35 \%$ for attending protests, $41 \%$ for voting and contacting officials, $44 \%$ for financial contributions, and $52 \%$ for contacting government officials. ${ }^{9}$ Broadening the focus of twin studies by including extended family members in heritability estimates produces much the same results. ${ }^{10,11}$

Studies looking at the heritability of political attitudes over time have found that environmental influences play a stronger role during childhood, while genetic influences assert themselves to a greater extent after children have left their parents' home. ${ }^{12,13}$ A rare study that investigated differences in heritability between right-wing and left-wing ideologies found that genetic influences on the development of left-wing ideology were more affected by the home environment, while genetic influences on the development of right-wing ideology were more affected by one's unique environment outside of the home. ${ }^{14}$

These sorts of results have also been found in crosscultural studies, with heritability estimates of political ideology varying across countries but remaining significant at an average level of around $40 \% .{ }^{15}$ Environmental influences on political ideology were found to vary much more dramatically across countries, leading the study's authors to conclude that "the genetic pathways undergirding political ideology remain similar in people of relatively similar genetic ancestry, but emerge in different manifestations within different cultures and variegated political environments. Genetic influences on political ideology are not boundless." 16

Overall, these studies seem to show that different sets of genes may create varying levels of susceptibility to particular political ideologies. ${ }^{17}$ It is not as though they suggest the existence of a "socialism" gene that disposes people to be favorable to socialism, or a "federal housing" gene that makes people support the idea of the 


\section{Development of political opinions}

government providing low-cost housing for the poor. Rather, these twin studies suggest that genes have broad effects on our individual psychology and personality, which, in turn, make us more likely to adopt one political position rather than another. For instance, genetic variations that affect one's sensitivity to fear may affect our reactions to unknown outsiders, making us more likely to take one or another stance on the issue of immigration policy. ${ }^{18}$ While some studies have suggested that genes affect personality variables, which, in turn, influence the development of political ideology, more recent work has cast doubt on this link. ${ }^{19}$ Some studies suggest that this link may be better explained by needs for cognition and cognitive closure influencing ideology. ${ }^{20}$ Cognitive ability, which has a genetic heritability component, has repeatedly been shown to dispose people toward left-wing ideology. ${ }^{21}$ What constitutes left-wing and right-wing ideology varies by cultural context, but the link between cognitive ability and left-wing ideology remains. ${ }^{22}$

After twin studies confirm that there is some degree of genetic heritability underlying political attitudes, the next step is to attempt to locate specific genes that may produce these population-level effects. The first step in this process has been to analyze portions of many people's genomes, identifying genetic similarities that correlate with similarities in political ideology. Many such regions were identified in one study, but only one area with a reliably high-correlation contained any gene known to be associated with human social behavior. ${ }^{23}$ Another way to proceed is by choosing a gene known to be associated with social behavior and testing a sample of people with and without it to measure differences in their behavior. This has been done for a gene associated with brain function, finding that those with a particular variant of the gene displayed more altruistic behavior than those without it. ${ }^{24}$ Studies of this sort can also test for environmental influences on genes. Accordingly, a gene associated with novelty-seeking behavior was found to correlate with left-wing political ideology. This effect increased as a function of the number of friends an individual had as a child. ${ }^{25}$

\section{Interpreting the results}

The conclusions of these types of studies, however, are not as straightforward as they might seem. A fundamental part of the problem is the incredibly complex way that genes work. For instance, an animal as simple as a fruit fly, with only 100,000 neurons compared with our 100 billion, has at least 266 separate genes that code for proteins known to be involved in varying levels of fruit fly aggression. Yet the heritability of aggression in fruit flies is only about $10 \% .{ }^{26}$ Causation in biological systems runs in two directions: upward from the genome and epigenome and downward from the environment, organism, organs, tissues, and even cells, with feedback and feed-forward loops between different levels. ${ }^{27}$ Also, because the genome is so large, finding correlations between genes and traits is highly likely to occur simply by chance, and extremely large sample sizes may be required to find anything significant. ${ }^{28}$ Hence, capturing individual genes' contributions to the heritability of political ideology seems to be a very distant goal from the perspective of today's science.

Twin studies in particular require careful, conservative interpretation. For instance, one twin study found that empathy was about $30 \%$ heritable, an estimate that is roughly in line with prior studies. ${ }^{29}$ Yet a metaanalysis of studies measuring levels of empathy in U.S. college students from 1979 to 2009 found that empathy decreased $34 \%$ to $48 \%$ during that time. ${ }^{30}$ Could $30 \%$ of this drop be explained by genes, or did people with a genetic propensity for empathy stop having as many children during these 30 years? Such an interpretation is highly unlikely, and thus the very precise-seeming heritability estimates produced by twin studies need to be taken with a grain of salt. First, heritability itself is a confusing term, as it seems as if it is a property of the trait itself, when it is actually just a description of the population in which the trait appears. ${ }^{31}$ Also, a high degree of heritability within a group says nothing about variation between groups. For example, most of the variation in political attitudes among Trinidadians may be genetic, but that does not mean that their political attitudes are (mostly) genetically transmitted. It means that Trinidadians exhibit genetic variation that affects political attitudes, and these effects are larger than the effects of environmental and cultural differences in Trinidad. This tells us little about Jamaicans or any other group. In addition, heritability estimates are known to be strongly affected by different environmental conditions alone. $32,33,34$

Apportioning variance in political ideology to either genetic or environmental factors is problematic from the start. ${ }^{35}$ The conceptual opposition between nature and nurture first arose in Anglo-American culture in the $1800 \mathrm{~s}$, and it has influenced science ever since but if "nature versus nurture" ever made sense, it most certainly does not today in light of modern genetics, ${ }^{36}$ as 
Charney explains - and the complexity of the phenomena continues to grow, for instance with long noncoding RNAs (lncRNAs):

"Inherited versus environmental," or "nature versus nurture," are artificial and superannuated dichotomies that distort the complexity of the phenomena. Trying to fit environmentally induced epigenetic activation of retrotransposons, or intergenerationally transmitted epigenetic reprogramming, into this dichotomous worldview as represented in standard quantitative genetic models is like trying to locate black holes within Aristotle's dichotomy of the sublunar world of change and the immutable heavens. ${ }^{37}$

More specifically, classic twin studies can only offer trustworthy, precise estimates of genetic and environmental contributions to a trait when all causal factors have been clearly demarcated and all causal factors act independently of each other. However, everything we know about biology tells us that it is complex, nonlinear, and nonadditive - making truly independent causal factors highly unlikely.

A key assumption of twin studies is that the environments experienced by identical twins are no different, on average, from the environments experienced by fraternal twins. This is how an estimate of heredity can be plucked out of data about similarities between identical and fraternal twins. If the identical twins are more alike than fraternal twins, it would seem that this extra similarity must be genetic, if there is nothing about identical twins' environments that is more similar than those of fraternal twins. Estimates of heritability rely on this assumption, and they are inflated to the extent that the environment shared by identical twins is actually more similar than the environment shared by fraternal twins. This would occur, for instance, if family members, teachers, and friends tended to treat identical twins more similarly than fraternal twins which is what studies of twins have found. ${ }^{38,39,40}$ This may be the source of the "mystery of missing heritability" arising from high estimates of heritability from twin studies, on the one hand, and, on the other, studies of the genome itself, which have turned up relatively few genes associated with various traits and explain only a fraction of the estimated heritability. Additionally, twin studies may likely produce inflated estimates for heredity by confounding purely genetic effects with gene-environment, and a host of potential genetic and epigenetic, interactions. ${ }^{41,42}$
Twin studies are useful for determining whether there are genetic effects on a particular trait, but they are less useful for determining how much. ${ }^{43}$ They are valuable for clearly demonstrating that some characteristics, such as political views, are assumed to be entirely environmentally determined but are in fact influenced by genes. At the same time, critiques of genome-wide association and gene-behavior linkage studies are correct in urging caution. The tools we have available can only make slow, step-by-step progress in understanding how genes and environment interact to produce our political dispositions. ${ }^{44}$

\section{What about environmental effects?}

While the results of genetic and neuroscientific research strongly suggest that there is a hardwired, heritable component to political orientation in our genes that expresses itself in the very structure of our brains, there is also evidence that our environments, too, can reshape our brains' structure. ${ }^{45,46}$ For instance, while left-wing and right-wing people display differences in the sizes and activity levels of certain brain structures, evidence suggests that involvement with partisan politics may help drive those differences irrespective of heredity. Changes in cognitive functions of other types are also known to lead to changes in brain structure, as when people studying a map of London for a taxi driver examination demonstrated significant growth in the brain region relating to memory formation. ${ }^{47}$ Therefore, while genetic influences certainly shape our brains in ways that make some ideologies more attractive, so, too, can our ideologies shape our psychological and physiological characteristics.

Environmental influences also help shape personality traits and shift political orientations. For instance, low socioeconomic status, which typically involves working in a low-status job with little autonomy, is a reliable predictor of obedience to authority, which correlates with right-wing political orientation. ${ }^{48}$ Genes may also influence media preferences, which, in turn, affect the development of ideology. ${ }^{49}$ Threatening events such as the September 11 terrorist attacks, by activating fear of death and threats to the system, subtly influence people to shift their political opinions rightward. ${ }^{50}$ Working in an occupation that requires the understanding and appreciation of multiple, conflicting arguments and evidence increases the likelihood of a leftward shift in opinions, as do education and travel. ${ }^{51} \mathrm{~A}$ study of voting records and economic performance in the United States 


\section{Development of political opinions}

over nearly a century found that a threatening economic environment influences voting toward the right, while a positive economic environment influences voting toward the left. ${ }^{52}$

\section{The chicken-and-egg problem of political psychology}

Given current limitations in our understanding of genetic etiology, epigenetics, and gene-environment interactions, a conclusive demonstration that either genetic or environmental factors are the predominant influence on the development of political ideology (and its neurological concomitants) seems quite far off, if not simply impossible a priori. However, we can at least begin to test whether Jost, Noorbaloochi, and Van Bavel's dynamic, recursive theory of bidirectional effects between physiological/psychological functioning and political ideology is incorrect in either of two ways: whether genetic influences clearly outweigh discursive, socially constructed influences or vice versa. Recent research has provided support for this theoretical approach by using statistical techniques to decompose variation in political ideology in economic, social, and military realms according to environmental and genetic factors, finding a different pattern of relationships at the two levels. ${ }^{53}$ Thus, genetic and environmental influences may not always work in concert but may pull in different or opposite directions, thereby producing a kaleidoscopic pattern of ideological components. ${ }^{54}$

Another way to perform such a test is to offer experimental participants a novel political proposal with clear ideological affinities: those with right-wing ideology should be unfavorably disposed, and those with left-wing ideology should be favorably disposed. Discursive influences can be introduced by providing varying (pro and con) pieces of information about the proposal. The information one has available is known to profoundly influence political opinions. ${ }^{55,56,57}$ Socially constructed influences (in this case, social status) can be introduced by means of a role-play manipulation. Role play, while in declining use in social psychology since the 1970s, has been effectively employed to manipulate independent variables in various contexts. ${ }^{58}$ Combined genetic-environmental influences on political ideology are already present among adult participants and can be measured, albeit coarsely, in the form of political ideology self-reports and reports on participants' parents' ideology. (Coarse measurement may be the best currently available; even if full genetic assays were available for hundreds of experimental participants, we still would not know which genes to look for.) Assuming current twin studies' estimates of heritability to be correct without qualification, around half of the total variation among participants' political ideology derives from genetic factors; the rest of the variation would be attributable to environmental factors. Likewise, making the same assumption, all else being equal, participants with both parents of the same ideology are more likely than participants with parents of differing ideologies to have whatever gene or set of genes that tends to dispose people to develop that ideology. Hence, having both parents with strong left-wing or right-wing ideology can stand in as a very rough proxy for (or, a greater likelihood of having) whatever gene or set of genes that predisposes people to develop left-wing or right-wing ideology. There are some additional sources of noise in this proxy measure that come from the possibility that some participants may have been adopted, that they may have inaccurately reported their parents' ideology, and that some of their parents may have changed ideologies during their lives.

This proxy may at first seem just as much the product of environmental as genetic factors. After all, even after controlling for income, one's parents' income may exert significant influence over one's wealth as a result of financial support, social network connections, investment advice, and so on. Likewise, after controlling for a child's measured intelligence, parents' intelligence may still affect academic performance, as a result of guidance at home, encouragement to study, greater availability of books, or other factors. This may be the same with measured ideology and parental ideology: after controlling for participants' ideology, parents' ideology may still affect the development of opinions on a novel political issue. However, the nongenetic avenues by which such an effect can occur are more limited in this instance. Accordingly, exposure to more political talk at home, reinforcement of ideology through contact with parents, and social network effects should all be exhaustively measured by one's own self-reported ideology. Nonetheless, it is possible that having strongly ideological parents may deepen the political commitments measured by self-reports, such that the same ideological self-placement by a participant with ideologically similar parents and one with ideologically dissimilar parents may indicate a stronger adherence to the same position on the ideological spectrum for the former than 
the latter. Therefore, even the genetic proxy should be considered to contain an environmental component.

If Jost, Noorbaloochi, and Van Bavel's dynamic, recursive, bidirectional theory is correct, then we would expect to see information, social status, ideology, and genetic ideological predisposition (measured through the rough proxy of having both parents with the same ideology) each independently contributing to the formation of opinions on a novel political proposal. If this theory is incorrect because genetic factors predominate, we would expect to see effects of ideology and genetic ideological predisposition (owing to that portion of the measures representing genetic influence, and in spite of the fact that both measures necessarily include some environmental influence) but little to no effects for social status and information exposure. Furthermore, if this theory is incorrect because environmental factors predominate, we would expect to see effects of social status and information exposure but reduced effects for ideology and little to no effects for the proxy measurement of genetic ideological predisposition. In other words, if ideology is disproportionately caused by genes, then role-played social status and exposure to information about the proposal should be insignificant - overwhelmed by hardwired neurological structures that produce ideology and lead to discounting ideologically uncongenial discursive and socially constructed factors - and participants' opinions should match their (and their parents') ideology. If ideology is disproportionately caused by discursive, socially constructed environmental factors, then role-played social status and exposure to information should dominate, with the other two variables providing limited influence (owing only to their discursive, environmental components and not to genetics). Therefore, H1: Information exposure, social status, ideology, and genetic ideological predisposition will each independently influence the development of opinions on a novel political issue.

\section{Research methods}

\section{Participants}

An M-Turk sample of 2,016 U.S. residents was collected for the survey (after eliminating 9\% of participants who failed the attention check and another $10 \%$ who reported a low level of engagement with the role play, $N=1,660$ ). This was a nonrepresentative convenience sample, more diverse than other internet and college student samples, although its subject pool tends to be younger and more liberal than the general U.S. population and includes a disproportionately large percentage of whites. ${ }^{59}$ The demographic characteristics of the sample were as follows: $59 \%$ female, $72 \%$ white, $6.5 \%$ black, 6\% Hispanic, 5\% Asian-American, and $9 \%$ other. Ages of the responded ranged from 17 to 76 $(\mathrm{M}=34.1$ years, $\mathrm{SD}=11.3$ years $)$. Asked to place their level of education on a 1-6 scale from "some high school" to "completed graduate school," participants' mean was 3.7 (between some college and completed college), median 4 (completed college), and mode 3 (some college). Asked to place themselves on a 0 (left/liberal) to 100 (right/conservative) scale, the average placement was 39.7 ( $\mathrm{SD}=26.4$ ); on economic issues, the average placement was closer to the center, at $45(\mathrm{SD}=28)$, and on social issues, the average placement was further left, at $34.7(\mathrm{SD}=28.4)$.

Ideology was measured by simple self-placement for three reasons. The first was to minimize the number of questions asked in an unavoidably long survey, reduce dropouts, and maximize attention. A second reason was for comparability across countries in future research; the simple left-right scale has been found to be appropriate for cross-national comparisons, obviating the need to tailor unique scales for different nations. ${ }^{60} \mathrm{~A}$ third reason was for comparability with past studies; while several studies use longer, issue-specific measurements, many others use simple self-placement measures, including the often-examined American National Election Study (and other countries' large-scale surveys). ${ }^{61}$ Furthermore, as discussed by Oskarsson et al., ${ }^{62}$ studies of the genes-ideology link sometimes use long batteries of questions (e.g., versions of the Wilson-Patterson scale) and sometimes use simple ideological self-placement (or partisanship/vote choice) - or both. Because studies of ideological heritability that have used both have not uncovered stark differences between the two, ${ }^{63}$ the simpler measure was chosen. However, as social and economic ideology can be orthogonal to each other, ${ }^{64}$ separate self-placement measures of social and economic ideology were used as well, in case the primarily economic proposal might be affected only by economic ideology and not social or overall political ideology.

\section{Materials}

Following the guidelines for successful role-play practice set out by Yardley-Matwiejczuk, participants were first introduced to the nature of the role play: what would require imaginative effort (putting oneself in the 


\section{Development of political opinions}

shoes of a fictional character in a fictional country) and what would not (the character should have the same "moral values" as the individual participant). They were then introduced to a short summary about the country of "Morapia," which was meant to be substantially similar to the United States (industrialized, fairly large, productive agricultural sector, etc.), and presented with a map of the country and its flag. Then, participants were randomly assigned to role-play as one of four gender-neutral characters: a humble farmer, a low-wage worker, the president of Morapia, or a wealthy business owner. A basic description of each role was provided, covering basic details of each character's life (residence, daily life, relationship with others, ability to control outcomes, etc.), and a picture of the character's home was displayed. Participants were asked to give their character a name, which was then used as the exclusive form of address in subsequent parts of the instrument.

Next, participants (addressed using their role-play character's name) were introduced to the Proposal, a three-part bill under consideration in Morapia, designed to touch on the key ideological divides between change versus the status quo and equality versus hierarchy. ${ }^{65,66}$ The proposal, if made law, would give workers one-third of the seats on all companies' boards of directors; taxes would be made more progressive; and land would be redistributed by government purchases from large landowners and sales to farmers working on the land using interest-free, 50-year loans. Each part of the Proposal was introduced along with pictures to illustrate the domain to be affected (workers, taxes, farmers). All three parts of the bill were in the direction of greater equality (versus hierarchy) and change (versus the status quo), such that more right-wing participants would be expected to reject the Proposal, and more left-wing participants would be expected to approve. To drive this point home, participants were told that "in general, those who favor this Proposal believe that Morapia must change to become a more equal society; those who oppose the Proposal believe that Morapia should stay the way it has been traditionally, with a hierarchy by merit." To dampen the effects that participants' economic theories might have, they were told that Morapian economists are evenly split on the Proposal, with equal numbers believing it would help or hurt the economy.

Participants were then asked to think about the merits of the Proposal while they sat in their favorite chair: a wooden chair in a modest farmhouse was pictured for the farmer, a metal-and-plastic kitchen chair in a studio apartment for the low-wage worker, an elegant chair behind an imposing desk in the presidential palace for the president of Morapia, and a cushioned leather chair in an ornately appointed study for the wealthy business owner. They were then presented with four pieces of information about the Proposal from four sources (favorite newspaper, favorite television news program, a trusted friend, and family members) and covering four aspects of the Proposal's effects (on economic health, social cohesion, workplace relations, and agricultural productivity) (see online Appendix 1).

\section{Procedures}

Participants were randomly assigned to one of the four roles and then presented with a neutral description of the Proposal, followed by information in favor of or in opposition to it, based on its likely effects. In random order, each participant got one piece of information from each of the four sources, covering each of the four aspects of the Proposal's effects, and was randomly assigned to receive either four negative, four positive, a 3:1 ratio of negative or positive, an even 2:2 split of negative and positive information, or no information at all (control).

Afterward, participants were asked to state their level of support (on a 0-100 sliding scale) for the Proposal, along with their opinions on the Proposal's effects on social cohesion, workplace relations, the Morapian economy, and agricultural productivity. Next, they were told that the role-playing portion was finished, and instead of answering as their character, they should proceed to answer the remaining questions as they would themselves. The remaining questions covered engagement with the role play, opinions on the Proposal, and standard demographic questions, including participants' political ideology (on a sliding scale from 0 , left/liberal, to 100 , right/conservative) and separate measures for economic and social issues as well as participants' mother and father.

The main dependent variable was participants' roleplay character's opinion of the Proposal; independent variables included demographic factors (age, gender, income, education), self-reported ideology, a dummy variable for rich/powerful or poor/powerless role-played social status, balance of negative-positive information*

\footnotetext{
* Because no significant differences were found between Proposal opinions in the information control group (no pieces of information) and those who received two pieces each of negative and positive information, control group members were coded as 0 along with those receiving a balanced set of information.
} 
(either $-4,-2,0,2$, or 4 ), and a proxy variable for genetic propensity to left-wing or right-wing ideology. The proxy variable was created by coding participants as -1 if both of parents were rated as left of center, 0 if both parents were rated at the political center or were of different political ideologies, and 1 if both parents were rated as right of center.

\section{Results}

First, one of the three measures of ideology (overall, economic, or social) needed to be selected for analyses of effects on role-played opinions on the Proposal. Because the Proposal was designed to tap into both acceptance-of-inequality and resistance-to-change aspects of ideology, any of the three would arguably be appropriate. However, self-reported economic ideology is inherently closer to the subject matter of the Proposal and should have the strongest effect on participants' evaluations; confirming this, economic ideology had a stronger correlation with both role-play and personal levels of support for the Proposal (respectively, $r=$ -0.451 and $-0.509, p<0.01)$ than either ideology overall (respectively, $r=-0.412$ and $-0.463, p<0.01$ ) or ideology on social issues (respectively, $r=-0.340$ and $-0.382, p<0.01)$. Therefore, self-reported ideology on economic issues was selected for analysis. (Results using the other ideological measures, including a combined measurement, were substantially similar; see online Appendix 2.)

To test for individual effects among the discursive, socially constructed influences, $t$-tests on mean differences in support for the Proposal were performed for each of the four roles. Role-played farmers averaged 69.9, low-wage workers averaged 71.3, presidents averaged 65.6, and wealthy business owners averaged 59.8 (higher scores indicate greater support). Differences between the two low-power, low-wealth roles were both significantly higher than either of the two high-power, high-wealth roles at the $p<0.05$ level. The averages for the farmers and low-wage workers were not significantly different, although the averages for the presidents and wealthy business owners were; this may be attributable to the fact that while a president has at least as much power as a wealthy business owner, he or she may not have as much wealth. Regardless, the mean difference in opinion between the two low-power roles (70.6) and high-power roles (62.8) was significant at the $p<0.001$ level. Likewise, exposure to information about the Proposal evinced significant effects: the correlation between the balance of negative to positive information and opinions on the Proposal was weak but significant $(r=0.222, p<0.01)$.

To test for individual effects among variables with a known genetic component, $t$-tests on mean differences in support for the Proposal were performed for the groups of participants with two left-wing parents, two right-wing parents, or two centrist or two ideologically diverse parents. Those with two left-wing parents averaged 73.8, those whose parents were neither both left-wing nor right-wing averaged 69 , and those with two right-wing parents averaged 61, with all differences significant at the $p<0.01$ level. Likewise, self-reported ideology on economic issues evinced significant effects on support for the Proposal: the correlation between left/liberal (0) to right/conservative (100) ideology and support for the Proposal was moderate and significant $(r=-0.451, p<0.01)$.

However, self-reported ideology comprises both environmental (exposure to political information) and genetic (propensity to left-wing or right-wing ideology) components. So, too, does the proxy measurement of genetic ideological propensity comprise environmental (parental influence on ideological development) and genetic (whatever genes predispose parents and their children to one or another ideology) components. Additionally, real-world factors such as participants' gender, age, and socioeconomic status (income and education) may also influence opinion on the Proposal. Therefore, to investigate the relative contribution of the several discursive and socially constructed influences and the combined genetic and environmental influences on the formation of opinions about the Proposal, two multiple regression models were employed. The first predicted role-play support for the Proposal, while the second predicted participants' personal support for the Proposal (Table 1).

Role-played social status, information, ideology, and genetic ideological predisposition each added a statistically significant contribution to the formation of opinions on the Proposal. So, too, did gender in the model of role-play opinions; in the model of personal opinions, income and education were significant predictors as well. The most striking difference between the two models is that in the role-play model, the effect of playing a powerful versus a powerless role has stronger effects. In the personal opinion model, role-play effects remain but are weakened; instead, participants' own social status (measured by income and education) takes on a significant predictive role. 


\section{Development of political opinions}

Table 1. Summary of multiple regression analysis for variables predicting opinions on the proposal $(N=1660)$.

\begin{tabular}{|c|c|c|c|c|c|c|}
\hline \multirow[b]{2}{*}{ Variable } & \multicolumn{3}{|c|}{ Role-play opinion } & \multicolumn{3}{|c|}{ Personal opinion } \\
\hline & $B$ & $S E B$ & $\beta$ & $B$ & SE B & $\beta$ \\
\hline Age & 0.044 & 0.056 & 0.017 & 0.056 & 0.057 & 0.021 \\
\hline Female & $4.56 * * *$ & 1.25 & $0.077 * * *$ & $3.84 \% *$ & 1.27 & $0.064 * *$ \\
\hline White & 0.485 & 1.37 & 0.008 & 0.387 & 1.39 & 0.006 \\
\hline Income & $-0.408^{\dagger}$ & 0.234 & $-0.039^{\dagger}$ & $-0.623 * *$ & 0.237 & $-0.058 * *$ \\
\hline Education & -0.831 & 0.559 & -0.033 & $-1.42 *$ & 0.567 & $-0.055^{*}$ \\
\hline Role-Play (powerful) & $-7.53 * *$ & 1.22 & $-0.130^{* * *}$ & $-2.58^{*}$ & 1.24 & $-0.043^{*}$ \\
\hline Information $(-$ to +$)$ & $2.39 * * *$ & 0.234 & $0.213 * * *$ & $1.57 * * *$ & 0.238 & $0.137 * * *$ \\
\hline Ideology (L to R) & $-0.434 * * *$ & 0.023 & $-0.418 * * *$ & $-0.509 * * *$ & 0.024 & $-0.478 * * *$ \\
\hline Gene proxy (L to $R$ ) & $-1.78 *$ & 0.824 & $-0.048^{*}$ & $-1.75^{*}$ & 0.836 & $-0.046^{*}$ \\
\hline $\mathrm{R}^{2}\left(\operatorname{Adj} . \mathrm{R}^{2}\right)$ & \multirow{2}{*}{\multicolumn{3}{|c|}{$\begin{array}{l}0.278(0.274) \\
70.31 \% \approx\end{array}$}} & \multicolumn{3}{|c|}{$0.295(0.291)$} \\
\hline$F$ & & & & $76.21 * * *$ & & \\
\hline
\end{tabular}

${ }^{* * *} p \leq 0.001 ;{ }^{* *} p \leq 0.01 ;{ }^{*} p \leq 05 ;{ }^{\dagger} p \leq 0.10$.
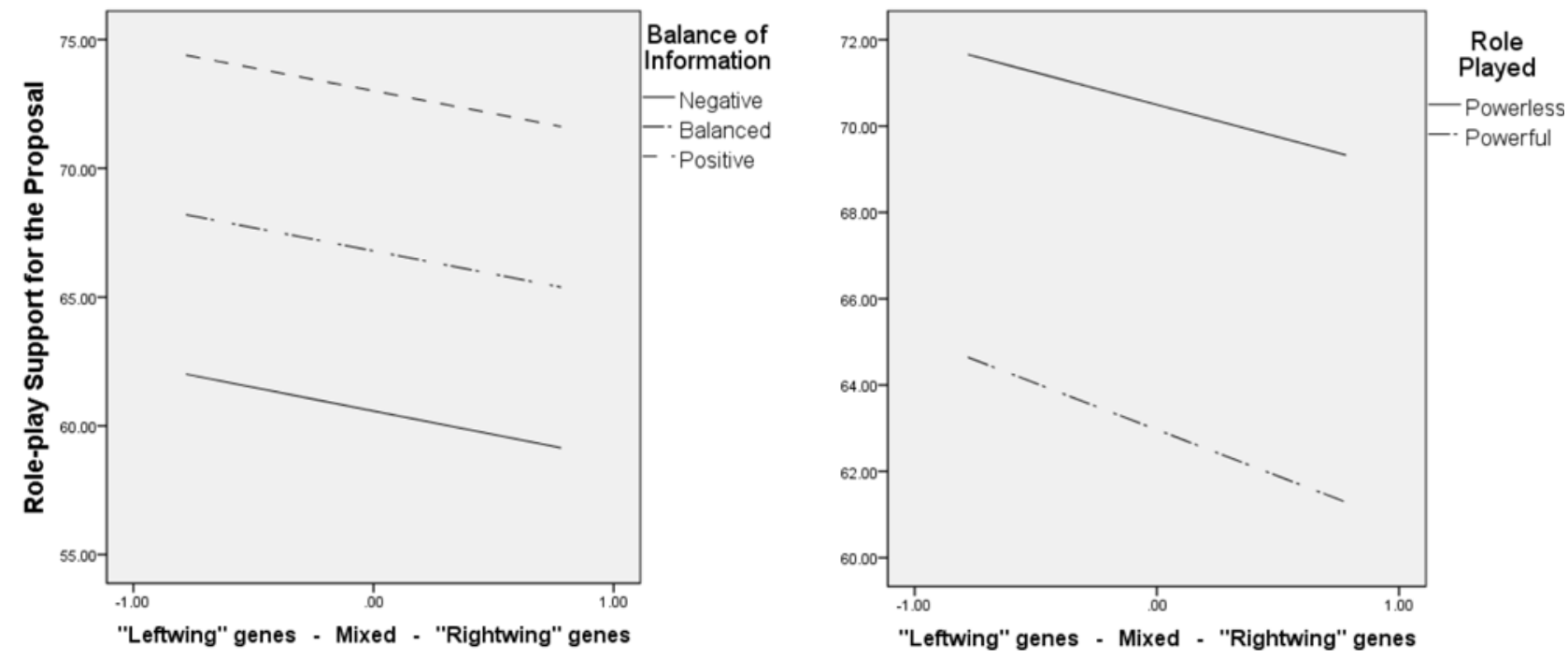

Figure 1. Role-play opinions model, controlling for all other variables.

\section{Discussion}

Lending support to $H 1$, information, role-played social status, ideology, and genetic ideological predisposition each contributed to the formation of opinions on the Proposal - both in isolation and in multiple regression analysis in which other factors were controlled. Most interestingly, the rough proxy for genetic ideological predisposition remained a significant predictor of opinions even after controlling for self-reported ideology. This is more surprising given the inherently noisy nature of this proxy measurement; of course, if no significance were found, this would not be evidence that genes play no role in the development of political opinions, and this measure could not be used to measure relative strength of influence versus other factors. If genes played no role in the development of ideology, we would expect the effects of parents' ideology to be subsumed entirely by participants' own self-reported ideology. That is, if one's parents' ideology affected one's own ideology through exclusively environmental means, there should be little measurable independent effect of parental ideology. The environmental influence of one's parents on ideology should be expressed entirely and exhaustively in self-reports of one's own political views - unless parents' environmental influence "deepens" commitment to a particular ideological self-placement, such that self-reported ideology 
measures something fundamentally different between those with ideologically similar and dissimilar parents. Regardless, even if we assume that self-reported ideology and parental ideology are both measurements of inextricable gene-environment interactions, and that the effects of both are due entirely to their environmental components, skeptics of genetic influence on ideology would still need to explain away the results of numerous twin studies suggesting the existence of purely genetic effects.

Contrariwise, if discursive, socially constructed factors played a negligible or no role in the formation of ideology, then the effects of role-played social status and information should be overwhelmed by participants' ideology and that of their parents (transmitted through genes). Instead, we see that the effects of the role play remain - in weakened form - once participants are asked for their own opinion on the Proposal rather than their role-play character's. When asked for their own personal opinion, the effects of role-playing (and, to a lesser extent, information exposure) are reduced, and participants' own socioeconomic status (income and education) emerges as a significant predictor. Participants' socioeconomic status then plays the same role as role-playing: higher status predicts lower support for the equality- and change-promoting Proposal.

These results provide some support for Jost, Federico, and Napier's view that ideology and its physiological correlates are not simply caused by genes or social/informational environments. Instead, the evidence suggests that causation comes from both directions. While genes expressing themselves in response to environmental conditions may produce an initial set of "elective affinities" — psychological dispositions that make left-wing or right-wing ideas more attractive our social and informational environment determines what ideas are available, which we may then be attracted to and eventually adopt. ${ }^{67}$ Genes and our physical, social, and informational environments jointly determine our political ideology.

Of course, it would be difficult to the point of logical impossibility to hold the view that one's political ideology develops in lockstep with genetic instructions, without any influence from one's environment. For one, such a view would prompt the question of how genes "for" opinions on limited government intervention in a capitalist economy or affirmative action for historically oppressed ethnic minorities could possibly have evolved in a blink of evolutionary time. Likewise, while opposition to genetic explanations of social phenomena may be more widespread ${ }^{68}$ it is no less untenable. On both empirical and theoretical grounds, it now seems unarguable that genes play a role in the formation of political ideology.

But the two sets of factors should not be considered in opposition to each other; it simply makes no sense to think in terms of "nurture versus nature," in this or any other domain. ${ }^{69}$ Basic psychological dispositions produced by an interplay between genetic and environmental factors pull one in a left or right direction, making some political ideas appear more attractive, or feel more right, than others. Just as some chemical compounds mix together while others repel each other (such as water and oil), we display elective affinities toward some ideas and aversion to others. Once a significant amount of political ideas has been learned, our brains start displaying signs of pleasure or reward when we are exposed to other ideas that fit with our left or right disposition and background knowledge. This can set in motion a snowballing process by which we adopt more ever more ideologically congenial ideas and even change our social and informational environments to accelerate the process. Meanwhile, our initial political disposition grows into an ever stronger, tightly organized, and knowledgeable ideological stance.

\section{Conclusion}

The answer to the chicken-and-egg question seems to be - at least within this nonrepresentative sample, with a very rough proxy measurement of genetic influences - both. Our political "elective affinities" are caused not by genes or socialization alone but by both interpenetrating forces at the same time. As Roy Bhaskar wrote about complex, open systems, statements of laws are unlikely to obtain, and are more accurately conceived as statements of tendencies, which "may be possessed unexercised, exercised unrealized, and realized unperceived (or undetected) by men; they may also be transformed." ${ }^{\prime 70}$ A child born in the United States with a generations-long right-wing pedigree, whom we would expect to have whatever genetic endowment produces a predisposition to right-wing ideas, would merely have a tendency to develop right-wing ideology; that tendency may go unexercised (or if exercised, unrealized) if the child were to grow up surrounded exclusively by left-wing ideas from friends, teachers, media, and political elites. That same tendency may be exercised and realized in a child growing up in an environment dominated by right-wing ideas, or even one in which both 


\section{Development of political opinions}

left-wing and right-wing ideas are equally available. That tendency may be transformed, in a sense, if the child were adopted by a Bahraini couple and through her elective affinity for right-wing ideas adopted as a stance in support of monarchy instead of U.S.-style conservatism.

To the extent that genetic influences on political ideology offend our sensibilities, are normatively worrisome, or challenge a belief in free will, future research may be able to help. If we wish to deny a causal role for genetic influences we feel are out of our control, research in the psychology of persuasion can investigate how messages or arguments can be formulated to "reach across the aisle" and avoid rejection by those whose elective affinities dispose them to dispose of them. More importantly, perhaps, we should seek to ensure that our educational and media systems do not load the dice by offering more for the development and deepening of any particular elective affinity, and instead provide open debate among a broad diversity of perspectives. There is vast space for improvement in these areas.

\section{Note}

Online Appendices 1 and 2 are available as supplementary material on Cambridge Core.

\section{Acknowledgements}

The author would like to thank Professor Chuansheng Chen at UCI for his help.

\section{References}

1. Avi Tuschman, Our Political Nature: The Evolutionary Origins of What Divides Us (Amherst, NY: Prometheus Books, 2013).

2. John T. Jost, Christopher M. Federico, and Jaime L. Napier, "Political ideology: its structure, functions, and elective affinities," Annual Review of Psychology, 2009, 60: 307-337, at p. 310.

3. John R. Hibbing, Kevin B. Smith, and John R. Alford, "Differences in negativity bias underlie variations in political ideology," Behavioral and Brain Sciences, 2014, 37: 297-350.

4. Darren Schreiber, Greg Fonzo, Alan N. Simmons, Christopher T. Dawes, Taru Flagan, James H. Fowler, and Martin P. Paulus, "Red brain, blue brain: evaluative processes differ in Democrats and Republicans," PLOS ONE, 2013, 8(2): e52970.
5. John T. Jost, Sharareh Noorbaloochi, and Jay J. Van Bavel, "The 'chicken-and-egg' problem in political neuroscience," Behavioral and Brain Sciences, 2014, 37(3): 317-318, at p. 317.

6. Evan Charney, "Behavior genetics and postgenomics," Behavioral and Brain Sciences, 2012, 35(5): 331-358.

7. John R. Alford, Carolyn L. Funk, and John R. Hibbing, "Are political orientations genetically transmitted?" American Political Science Review, 2005, 99(2): 153-167.

8. Carolyn L. Funk, "Genetic foundations of political behavior," in The Oxford Handbook of Political Psychology, Leonie Huddy, David O. Sears, and Jack S. Levy, eds. (Oxford: Oxford University Press, 2013), pp. 237-261.

9. Dawes Christopher, David Cesarini, James H. Fowler, Magnus Johannesson, Patrik K. E. Magnusson, and Sven Oskarsson, "The relationship between genes, psychological traits, and political participation," American Journal of Political Science, 2014, 58(4): 888-903.

10. Peter K. Hatemi, John R. Hibbing, Sarah E. Medland, Matthew C. Keller, John R. Alford, Kevin B. Smith, Nicholas G. Martin, and Lindon J. Eaves, "Not by twins alone: using the extended family design to investigate genetic influence on political beliefs," American Journal of Political Science, 2010, 54(3): 798-814.

11. Christian Kandler, Wiebke Bleidorn, and Rainer Riemann, "Left or right? Sources of political orientation: the roles of genetic factors, cultural transmission, assortative mating, and personality," Journal of Personality and Social Psychology, 2012, 102(3): 633-645.

12. Lindon Eaves, Nicholas Martin, Andrew Heath, Richard Schieken, Joanne Meyer, Judy Silberg, Michael Neale, and Linda Corey, "Age changes in the causes of individual differences in conservatism," Behavior Genetics, 1997, 27(2): 121-124.

13. Peter K. Hatemi, Carolyn L. Funk, Sarah E. Medland, Hermine M. Maes, Judy L. Silberg, Nicholas G. Martin, and Lindon J. Eaves, "Genetic and environmental transmission of political attitudes over a life time," Journal of Politics, 2009, 71(3): 1141-1156.

14. Inga Schwabe, Wilfried Jonker, and Stéphanie M. Berg, "Genes, culture and conservatism - a psychometric-genetic approach,” Behavior Genetics, 2016, 46(4): 516-528.

15. Peter K. Hatemi, Sarah E. Medland, Robert Klemmensen, Sven Oskarsson, Levente Littvay, Christopher T. Dawes, and Brad Verhulst et al., "Genetic influences on political ideologies: twin analyses of 
19 measures of political ideologies from five democracies and genome-wide findings from three populations," Behavior Genetics, 2014, 44(3): 282-294.

16. Hatemi et al., 2014, p. 291.

17. Kevin Smith, John R. Alford, Peter K. Hatemi, Lindon J. Eaves, Carolyn Funk, and John R. Hibbing, "Biology, ideology, and epistemology: how do we know political attitudes are inherited and why should we care?" American Journal of Political Science, 2012, 56(1): 17-33.

18. Peter K. Hatemi, Lindon Eaves, and Rose McDermott, "It's the end of ideology as we know it," Journal of Theoretical Politics, 2012, 24(3): 345-369.

19. Peter K. Hatemi and Brad Verhulst, "Political attitudes develop independently of personality traits," PLOS ONE, 2015, 10(3): e0118106.

20. Aleksander Ksiazkiewicz, Steven Ludeke, and Robert Krueger, "The role of cognitive style in the link between genes and political ideology,” Political Psychology, 2016, 37(6): 761-776.

21. Emma Onraet, Alain Van Hiel, Kristof Dhont, Gordon Hodson, Mark Schittekatte, and Sarah De Pauw, “The association of cognitive ability with right-wing ideological attitudes and prejudice: a meta-analytic review," European Journal of Personality, 2015, 29(6): 599-621.

22. Sven Oskarsson, David Cesarini, Christopher T. Dawes, James H. Fowler, Magnus Johannesson, Patrik K. E. Magnusson, and Jan Teorell, "Linking genes and political orientations: testing the cognitive ability as mediator hypothesis," Political Psychology, 2015, 36(6): 649-665.

23. Peter K. Hatemi, Nathan A. Gillespie, Lindon J. Eaves, Brion S. Maher, Bradley T. Webb, Andrew C. Heath, and Sarah E. Medland et al., "A genome-wide analysis of liberal and conservative political attitudes," Journal of Politics, 2011, 73(1): 271-285.

24. Martin Reuter, Clemens Frenzel, Nora T. Walter, Sebastian Markett, and Christian Montag, "Investigating the genetic basis of altruism: the role of the COMT Val158Met polymorphism," Social Cognitive and Affective Neuroscience, 2011, 6(5): 662-668.

25. Jaime E. Settle, Christopher T. Dawes, Nicholas A. Christakis, and James H. Fowler, "Friendships moderate an association between a dopamine gene variant and political ideology," Journal of Politics, 2010, 72(4): 1189-1198.
26. Evan Charney and William English, "Candidate genes and political behavior," American Political Science Review, 2012, 106(1): 1-34.

27. Evan Charney and William English, "Genopolitics and the science of genetics," American Political Science Review, 2013, 107(2): 382-395.

28. Daniel J. Benjamin, David Cesarini, Matthijs J. H. M. van der Loos, Christopher T. Dawes, Philipp D. Koellinger, Patrik K. E. Magnusson, and Christopher F. Chabris et al., "The genetic architecture of economic and political preferences," Proceedings of the National Academy of Sciences, 2012, 109(21): 8026-8031.

29. Mark H. Davis, Carol Luce, and Stephen J. Kraus, “The heritability of characteristics associated with dispositional empathy," Journal of Personality, 1994, 62(3): 369-391.

30. Sara H. Konrath, Edward H. O’Brien, and Courtney Hsing, "Changes in dispositional empathy in American college students over time: a meta-analysis," Personality and Social Psychology Review, 2011, 15(2): 180-198.

31. Jonathan Marks, What It Means to Be $98 \%$ Chimpanzee: Apes, People, and their Genes (Berkeley: University of California Press, 2002).

32. Jon Beckwith and Corey A. Morris, "Twin studies of political behavior: untenable assumptions?" Perspectives on Politics, 2008, 6(4): 785-791.

33. Christopher Ojeda, "The effect of $9 / 11$ on the heritability of political trust," Political Psychology, 2014, 37(1): 73-88.

34. Doris Shultziner, "Genes and politics: a new explanation and evaluation of twin study: results and association studies in political science," Political Analysis, 2013, 21(3): $350-367$.

35. Ilan Dar-Nimrod, "Postgenomics and genetic essentialism," Behavioral and Brain Sciences, 2012, 35(5): 362-363.

36. Evelyn Fox Keller, The Mirage of a Space between Nature and Nurture (Durham, NC: Duke University Press, 2010).

37. Evan Charney, "Humans, fruit flies, and automatons," Behavioral and Brain Sciences, 2012, 35(5): 381-410, at p. 386.

38. Allan V. Horwitz, Tami M. Videon, Mark F. Schmitz, and Diane Davis, "Double vision: reply to Freese and Powell," Journal of Health and Social Behavior, 2003, 44(2): 136-141.

39. Jay Joseph, "The genetics of political attitudes and behavior: claims and refutations," Ethical Human Psychology and Psychiatry, 2010, 12(3): 200-217. 


\section{Development of political opinions}

40. Cf., Levente Littvay, "Do heritability estimates of political phenotypes suffer from an equal environment assumption violation? Evidence from an empirical study," Twin Research and Human Genetics, 2012, 15(1): 6-14.

41. Charney, 2012

42. Or Zuk, Eliana Hechter, Shamil R. Sunyaev, and Eric S. Lander, "The mystery of missing heritability: genetic interactions create phantom heritability," Proceedings of the National Academy of Sciences, 2012, 109(4): 1193-1198.

43. Wim E. Crusio, "Heritability estimates in behavior genetics: Wasn't that station passed long ago?" Behavioral and Brain Sciences, 2012, 35(5): 361-362.

44. James H. Fowler and Christopher T. Dawes, "In defense of genopolitics," American Political Science Review, 2013, 107(2): 362-374.

45. John T. Jost, Hannah Nam, David M. Amodio, and Jay J. Van Bavel, "Political neuroscience: the beginning of a beautiful friendship," Political Psychology, 2014, 35(S1): $3-42$.

46. Jost, Noorbaloochi, and Van Bavel, 2014.

47. Katherine Woollett and Eleanor A. Maguire, "Acquiring 'the knowledge' of London's layout drives structural brain changes," Current Biology, 2011, 21(24): 2109-2114.

48. Jaime L. Napier and John T. Jost, "The 'antidemocratic personality' revisited: a cross-national investigation of working-class authoritarianism," Journal of Social Issues, 2008, 64(3): 595-617.

49. Xiaowen $\mathrm{Xu}$ and Jordan B. Peterson, "Differences in media preference mediate the link between personality and political orientation," Political Psychology, 2017, 38(1): $55-72$.

50. Jost, Federico, and Napier, 2009.

51. John T. Jost, Brian A. Nosek, and Samuel D. Gosling, "Ideology: its resurgence in social, personality, and political psychology," Perspectives on Psychological Science, 2008, 3(2): 126-136, at pp. 133-134.

52. Jan-Emmanuel De Neve, "Ideological change and the economics of voting behavior in the US, 1920-2008," Electoral Studies, 2014, 34: 27-38.

53. Brad Verhulst, Peter K. Hatemi, and Lindon Eaves, "Disentangling the importance of psychological predispositions and social constructions in the organization of American political ideology," Political Psychology, 2012, 33(3): 375-393.

54. Hatemi, Eaves, and McDermott, 2012.
55. Scott L. Althaus, "Information effects in collective preferences," American Political Science Review, 1998, 92(3): $545-558$

56. Peter Beattie, "Information: evolution, psychology, and politics," Papers on Social Representations, 2016, 25(1): $1-37$.

57. Jeffrey Friedman, No Exit: The Problem with Technocracy (forthcoming).

58. For a comprehensive review, see, Krysia M. YardleyMatwiejczuk, Role Play: Theory and Practice (London: Sage, 1997).

59. Adam J. Berinsky, Gregory A. Huber, and Gabriel S. Lenz, "Evaluating online labor markets for experimental research: Amazon.com's Mechanical Turk," Political Analysis, 2012, 20(3): 351-368.

60. John D. Huber, "Values and partisanship in left-right orientations: measuring ideology," European Journal of Political Research, 1989, 17(5): 599-621.

61. Guillem Rico and M. Kent Jennings, "The formation of left-right identification: pathways and correlates of parental influence," Political Psychology, 2015, 37(2): 237-252.

62. Oskarsson et al., 2015, p. 653.

63. Carolyn L. Funk, Kevin B. Smith, John R. Alford, Matthew V. Hibbing, Nicholas R. Eaton, Robert F. Krueger, Lindon J. Eaves, and John R. Hibbing, "Genetic and environmental transmission of political orientations," Political Psychology, 2013, 34(6): 805-819.

64. Jost, Federico, and Napier, 2009.

65. Jost, Federico, and Napier, 2009.

66. Christian Kandler, Wiebke Bleidorn, and Rainer Riemann, "Left or right? Sources of political orientation: the roles of genetic factors, cultural transmission, assortative mating, and personality," Journal of Personality and Social Psychology, 2012, 102(3): 633-645.

67. Jost, Federico, and Napier, 2009.

68. Jennifer Hochschild and Maya Sen, "Technology optimism or pessimism about genomic science: variation among experts and scholarly disciplines," Annals of the American Academy of Political and Social Science, 2015, 658(1): 236-252.

69. Keller, 2010.

70. Roy Bhaskar, A Realist Theory of Science (New York: Verso, 1975/2008), p. 18. 